\title{
Substantial impacts of subsistence fishing on the population status of an Endangered reef predator at a remote coral atoll
}

\author{
Robert J. Lennox ${ }^{1,2, *}$, Alexander Filous ${ }^{2,3,4}$, Steven J. Cooke ${ }^{1}$, Andy J. Danylchuk ${ }^{2,3}$ \\ ${ }^{1}$ Fish Ecology and Conservation Physiology Laboratory, Department of Biology, Carleton University, Ottawa, \\ Ontario K1S 5B6, Canada \\ ${ }^{2}$ Indifly, PO Box 4460, St Paul, Minnesota 55104, USA \\ ${ }^{3}$ Department of Environmental Conservation, University of Massachusetts Amherst, 160 Holdsworth Way, Amherst, \\ Massachusetts 01003, USA \\ ${ }^{4}$ The Island Initiative, Papeete, French Polynesia
}

\begin{abstract}
Napoleon wrasse Cheilinus undulatus has declined drastically throughout most of its range, owing, in large part, to overexploitation. In Anaa, French Polynesia, the species is harvested as part of the subsistence catch by fishers using rockpile traps, spearguns, handmade harpoons, and baited handlines. We sampled 70 Napoleon wrasse captured by artisanal fishers of Anaa between 2015 and 2018 to assess the status of this population, and we applied data-poor fisheries models to assess the stock status of this iconic reef predator. The species was determined to be overexploited at a rate of 0.82 based on values of natural $(0.14$; Hoenig method) and fishing $(0.58$; difference of total and natural mortality) mortality as components of total mortality $(0.72$; Beverton-Holt estimation). The left-skewed length distribution (mean $=36 \pm 13 \mathrm{~cm} \mathrm{SL}$ ) suggested an under-representation of large adults in the population, which would predominantly be terminal males in this sequentially hermaphroditic protogynous fish. This was not considered to be reflective of poor selectivity by gear types but could have arisen as a consequence of unequal accessibility of exceptionally deep habitats off the reef shelf. According to the length-based spawning potential ratio, Napoleon wrasse is fully recruited to this fishery prior to $50 \%$ maturation and $50 \%$ sex changing, with the spawning potential ratio estimated to be $6 \%$, a characteristic of a highly overexploited species. Fishers were unselective towards size classes and harvest whatever they catch. Our analysis shows that even undirected, non-selective subsistence fishing yields overexploitation of this Endangered species.
\end{abstract}

KEY WORDS: Coral reef - Fisheries modeling - Spawning potential ratio · Sequential hermaphrodite $\cdot$ Harvest

\section{INTRODUCTION}

Worldwide, large predators are considered to be among the most vulnerable animals to fishing pressure (Myers \& Worm 2003). Larger and longer-lived fishes tend to be at greater extinction risk (Olden et al. 2007), as exemplified by the endangered status of large predatory ichthyofauna such as goliath

${ }^{*}$ Corresponding author: robertlennox9@gmail.com grouper Epinephelus itajara and Napoleon wrasse Cheilinus undulatus (Myers \& Worm 2003). Large predators have significant ecological roles but are inherently rare in both aquatic and terrestrial habitats (Purvis et al. 2000). On coral reefs, predators control abundances of other species by regulating population dynamics of some of their prey and restricting resources of their subordinates (Stallings

() The authors 2019. Open Access under Creative Commons by Attribution Licence. Use, distribution and reproduction are unrestricted. Authors and original publication must be credited. 
2008). Coral reef predators in many Pacific islands are highly valued for non-extractive resource capitalization, such as snorkel/SCUBA diving, but are also particularly valued as fisheries resources, including commercial, recreational, and subsistence fisheries. Loss of predators on coral reefs has been linked to changes in ecosystem dynamics, especially the competitive release of corallivorous species that erode the reef (Dulvy et al. 2004). Reef sharks represent a prominent predator on coral reefs, but their trophic levels and ecological roles suggest they are at a similar trophic level to most large predatory teleosts that also dominate the reef environment (Roff et al. 2016).

Napoleon wrasse is a large coral reef predator that is threatened with extinction in much of its shrinking range in the tropical Pacific Ocean (Sadovy et al. 2003). On reefs, this species provides an important ecosystem service as a predator of the corallivorous crown-of-thorns starfish Acanthaster planci (Randall et al. 1978) that has drastically impacted these invertebrate ecosystem engineers throughout the Pacific Ocean (Kayal et al. 2012). Napoleon wrasse is highly sought-after for the live-fish trade, is overfished in many locations within its range, and is an endangered species globally (Gillett \& Lightfoot 2001, Sadovy et al. 2003, Poh \& Fanning 2012, Kindsvater et al. 2017). The species is vulnerable to fishing by many methods including destructive practices (e.g. cyanide poisoning) because it commands high prices as an illegally traded species. Despite its international market and global extinction risk, it remains an important component of the subsistence harvest in coral atolls such as those belonging to the Tuamotu archipelago in French Polynesia (Gillett \& Lightfoot 2001, A. Filous et al. unpubl. data). Although the species is heavily exploited throughout its range, the scarcity of Napoleon wrasse renders it difficult to develop fishing targets and establish management objectives for the subsistence fisheries where it is harvested and supports nutritional security (Gillett \& Lightfoot 2001, Sadovy et al. 2007).

Data-poor fisheries management techniques are emerging to fill gaps in knowledge resulting from capacity deficits (FAO 2003, Hordyk et al. 2015, Prince et al. 2015a,b). In the absence of time series data reflecting changes in abundance, especially with pre-fishery baseline data, it can be challenging to assess a population and implement fisheries management. This problem is emblematic of many tropical fisheries for which assessments are further complicated by data deficiencies with respect to the fished species (Hordyk et al. 2015). Reproductive potential of a recruit is calculated by summing the fecundity of individuals as a function of their size in consideration of fishing mortality (Goodyear 1977, 1993). The spawning potential ratio then estimates the production lost to fishing and is applied in fisheries science where length distributions of captured or observed fishes can be modelled against known life history parameters. Methods for estimating exploitation, yield-per-recruit, and spawning potential ratio have been demonstrated useful tools for evaluating the status of reef fish populations, including those in the Indo-Pacific (Prince et al. 2015a). To evaluate the legacy of subsistence exploitation on the Endangered Napoleon wrasse (Russell 2014), we applied length-based data-poor fisheries analyses to compare the observed status of a population in a sparsely populated coral atoll to the simulated distribution of an ideal population based on published life history parameters (Choat et al. 2006, Froese \& Pauly 2018).

\section{MATERIALS AND METHODS}

Napoleon wrasse Cheilinus undulatus were sampled from fishers that captured them in the subsistence fishery in Anaa, French Polynesia. Anaa is a remote coral atoll that is oriented north-south in the Tuamotu Archipelago (Fig. 1). The atoll is home to

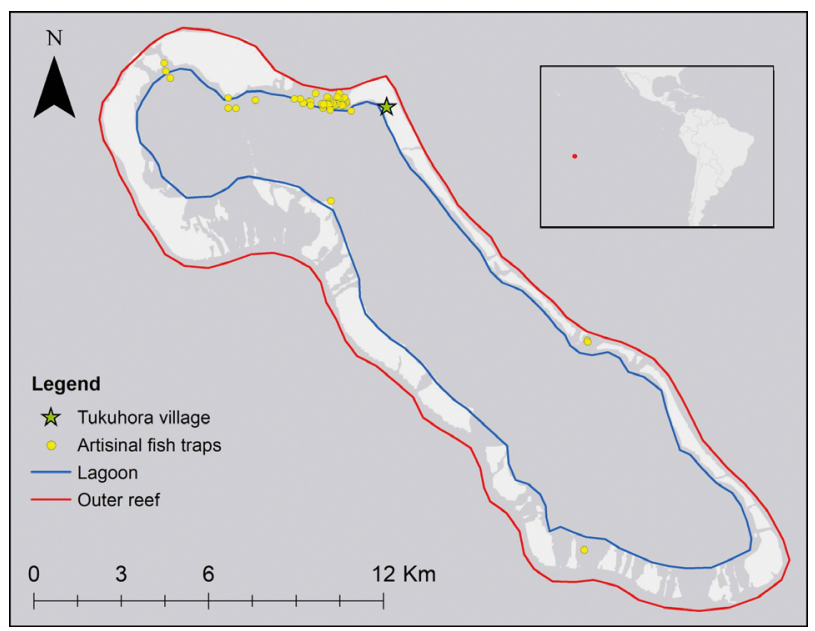

Fig. 1. Anaa Atoll $\left(17.410^{\circ} \mathrm{S}, 145.493^{\circ} \mathrm{W}\right)$ in the Tuamotu Archipelago of French Polynesia. Anaa is located $\sim 66 \mathrm{~km}$ from the nearest atoll. There is one village, Tukuhora (green star), with $\sim 400$ permanent residents. The inner lagoon (delineated by the blue ring) measures $\sim 90 \mathrm{~km}^{2}$. The back reef habitat falls between the blue and red rings in the figure and the outer reef beyond the red ring. Public and private artisanal fish traps are noted by yellow points 
400 permanent residents who rely on fisheries resources for subsistence (A. Filous et al. unpubl data). A shallow lagoon measuring $\sim 90 \mathrm{~km}^{2}$ is bordered by a coral reef (Fig. 1); both the lagoon and atoll support abundant marine fisheries resources, including fish, giant clams, cephalopods, and arthropods, but fish are the predominant species harvested by the subsistence fishery. Napoleon wrasse measurements were taken on a volunteer basis from subsistence fishers between October 2015 and March 2018. Standard lengths were measured for $\mathrm{Na}$ poleon wrasse captured in 20 different catches and gear types, whereas habitat types fished were recorded to understand the efforts expended by fishers to capture the species. In 3 instances in which only fork length (FL) was measured, we converted to standard length (SL) using a regression equation developed from our dataset wherein SL $=3.42+0.73 \times \mathrm{FL}\left(\mathrm{R}^{2}{ }_{\text {adj }}=93 \%, \mathrm{p}\right.$ $<0.001)$; we applied the same equation to convert coefficients published in FL or total length (TL; ostensibly equal for this species) such that all our analyses are based on standard length.

\subsection{Data analysis}

Length-based indicators were used to model the status of the Napoleon wrasse population at Anaa. Demographic parameters were selected from published material (Table 1) to calculate the spawning potential ratio (SPR) of the Napoleon wrasse in Anaa based on the size distribution observed in the subsistence fishery (Goodyear 1993, Hordyk 2017). Input parameters for the calculation of SPR are the asymptotic length $\left(L_{\text {inf }}\right)$, lengths at $50 \%\left(L_{50}\right)$ and $95 \%$ maturity $\left(L_{95}\right)$, and the ratio of natural mortality and growth rate (MK).

For Anaa, we had no information about the asymptotic length of Napoleon wrasse, so we reviewed literature from various nations that have described $L_{\text {inf }}$ of $C$. undulatus. Maximum lengths of $229 \mathrm{~cm}$ SL and $397 \mathrm{~cm}$ FL have been reported (Table 1), but to be conservative, we limited our value to 138 cm FL (104 cm SL; Kitalong et al. 1994, Table 1). We then used the growth rate $(K)$

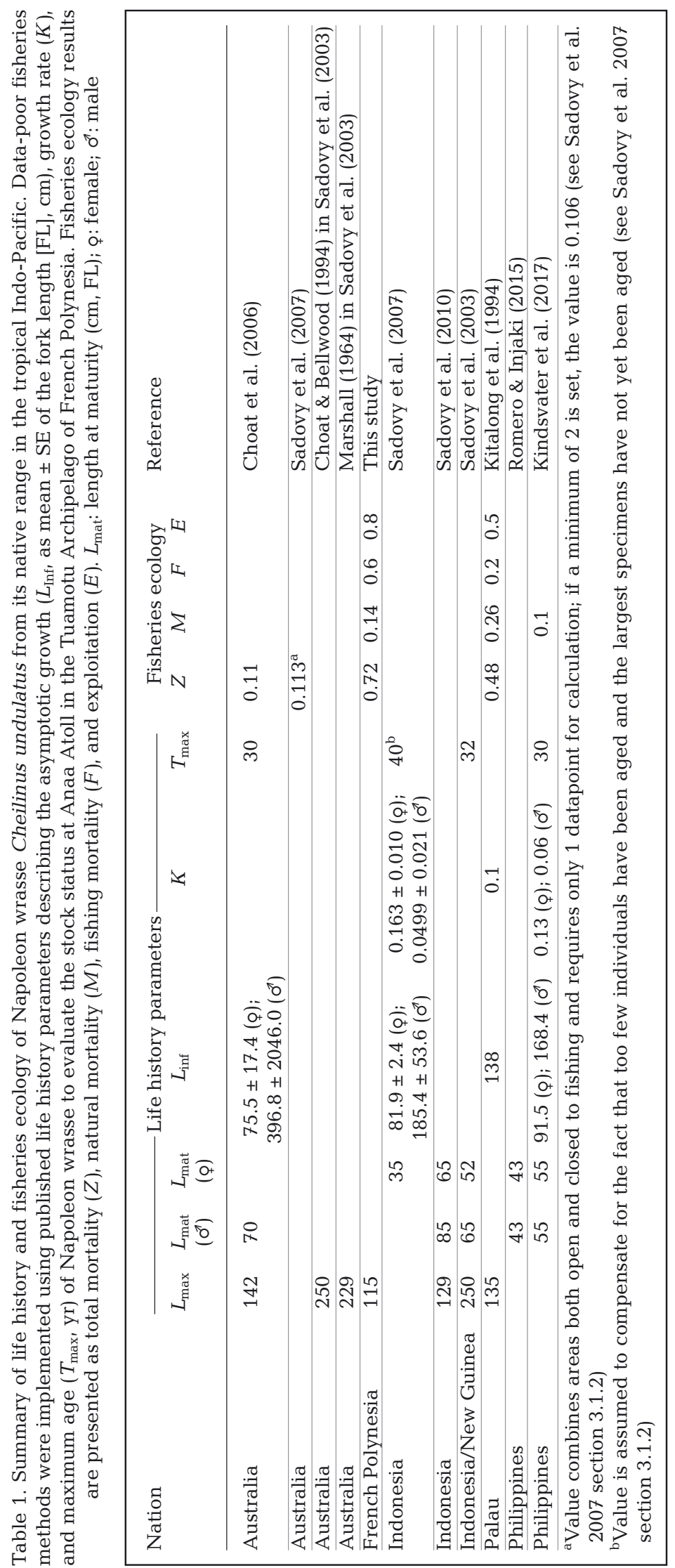


coefficient of 0.1 from the same study. The $L_{c_{c}}$ length at first capture, was the mode of the lengths recorded for Napoleon wrasse in the fishery at Anaa (29 cm SL). Lengths at maturity $\left(L_{50}\right.$ and $\left.L_{95}\right)$ were borrowed from data in Choat et al. (2006) using curves suggested by Sadovy et al. (2007) to only include mature fish, such that $L_{50}=35 \mathrm{~cm}$ FL $(29 \mathrm{~cm}$ SL) and $L_{95}=68 \mathrm{~cm}$ FL (53 cm SL).

Instantaneous mortality of the population was estimated using the Beverton-Holt equilibrium estimator (Ehrhardt \& Ault 1992) using the bheq function in the R package fishmethods (Eq. 1 in Nelson 2017). Fishing mortality was calculated as the difference between the parameter of instantaneous mortality, $Z$, and natural mortality (Table 1 ). Given that natural mortality of species is difficult to know on the time scales available for study, the rate of natural mortality was estimated for the species using the M.empirical function in fishmethods returning the Pauly (1980) and Hoenig (1983) estimates for fish (Eqs. 2 \& 3 in Nelson 2017). Without knowing the longevity of Napoleon wrasse in Anaa, we opted to use a value from the literature, 30 yr (Choat et al. 2006), which was more conservative than that suggested by Sadovy et al. (2007), who stated that the value of $32 \mathrm{yr}$ is predicated on incomplete age data (see Table 1). Fishing mortality is therefore the difference between total mortality and natural mortality, and exploitation rate was calculated as the quotient of fishing mortality and total mortality.

The value of MK was estimated to be 1.3, a relatively large ratio characteristic of a species in which large individuals are rare (Hordyk et al. 2015); this represents Type II as categorized by Prince et al. (2015a), a group including tropical snappers Lutjanus spp. and orange roughy Hoplostethus atlanticus. All parameters were passed to the LBSPRfit function in the R package LBSPR (Hordyk 2017). Results from the function yield an estimate of the population SPR as well as the selectivity in the fishery. Although measurements were taken over $2.5 \mathrm{yr}$, for the purposes of analysis and to compensate for small sample size, the values were grouped together as though taken from $1 \mathrm{yr}$ of sampling. We evaluate findings in the context of a $40 \%$ target SPR (Walters \& Martell 2004, Hordyk et al. 2015, Prince et al. 2015a). In consideration of possible sensitivities to parameter estimates, we fit additional rationalizable models using alternative values (Table 1).

Additional values of SPR were calculated using different coefficients from the literature to test the sensitivity of our model.

\subsection{Equations}

$Z=\frac{K\left(L_{\infty}-\bar{L}\right)}{-L_{\mathrm{C}}}$

where $K$ is the von Bertalanffy growth rate, $L_{\infty}$ is the asymptotic growth, $\bar{L}$ is the mean length of the catch, and $L_{C}$ is the first capture length (mode of lengths).

$$
\begin{aligned}
& \log (M)=-0.0066-0.279\left[\log \left(L_{\text {inf }}\right)\right] \\
& +0.6543[\log (K)]+0.4634[\log (T)]
\end{aligned}
$$

where $L_{\text {inf }}$ is the asymptotic length, $K$ is the growth rate, and $T$ is the environmental temperature, $27.5^{\circ} \mathrm{C}$ (A. Filous unpubl. data).

$$
\ln (Z)=1.46-1.01\left[\ln \left(T_{\max }\right)\right]
$$

where $T_{\max }$ is the maximum age.

\section{RESULTS}

Seventy Napoleon wrasse Cheilinus undulatus were sampled from the subsistence fishery during an $881 \mathrm{~d}$ period from 2015 to 2018. Five Napoleon wrasse (30 to $72 \mathrm{~cm} \mathrm{SL}$ ) were opportunistically dissected, and none revealed eggs or ripe gonads. Napoleon wrasse were predominantly captured fishing with a baited handline $(N=25)$, a method associated with the back-reef habitat surrounding the outer coast of the lagoon where 17 of those 25 were captured. One large catch of Napoleon wrasse was recorded $(\mathrm{N}=24)$ in which a group of small fish (mean $=33 \pm 4 \mathrm{~cm} \mathrm{SL}$ ) was corralled by a team of 5 fishers into a hole in the back reef where they were blockaded with stones and picked up by hand. Nine of the Napoleon wrasse were trapped in the artisanal fish traps placed in the passes between the lagoon and back reef. Nevertheless, all methods captured similarly sized Napoleon wrasse except the speargun, which captured 6 fish ranging more broadly in size (mean $=65 \pm 25 \mathrm{~cm} \mathrm{SL}$ ). Spearfishers harvested Napoleon wrasse while the wrasse were sleeping at night or chased freeswimming Napoleon wrasse until the wrasse took refuge in rock crevices where they shot them or blockaded the entrance to the cave with dead coral, returning the following day to harvest the fish that returned to the cave entrance. Effort data recorded from sampling the subsistence fishery (see A. Filous et al. unpubl. data) yielded catch efficiencies of 0.02 fish $\mathrm{h}^{-1}$ of spearfishing, 0.03 fish $\mathrm{h}^{-1}$ of harpoon fishing, 0.07 fish $\mathrm{h}^{-1}$ for handlining, and 0.21 fish $\mathrm{h}^{-1}$ for handfishing, which was a more opportunistic method of fishing and not something fishers left home with 
the intention of practicing (except for molluscs and crustaceans). The size distribution of harvested Napoleon wrasse was left-skewed with a long right tail suggestive of rarity in all the largest size classes. The mean length of harvested Napoleon wrasse was $36 \pm$ $13 \mathrm{~cm} \mathrm{SL}$, and the largest Napoleon wrasse measured $87 \mathrm{~cm}$ SL (115 cm FL) and was harvested by speargun while taking refuge under a coral head within the lagoon (Fig. 2).

Total mortality of Napoleon wrasse in the fishery was calculated to be $0.72 \pm 0.15 \mathrm{SE}$ based on the Beverton-Holt estimator. Natural mortality as calculated by the Pauly (1980) method was 0.26 and 0.14 for the Hoenig (1983) method, which is more similar to the value calculated by Choat et al. (2006) for Napoleon wrasse in Australia (0.14). Advancing with the Hoenig estimate of 0.14 annual natural mortality yielded a fishing mortality of 0.58 and an exploitation rate of 0.81 , suggesting overexploitation relative to the conventional cut-off of 0.50 . The spawning potential ratio of the Napoleon wrasse population at Anaa was determined to be $6 \%$ based on the length distribution observed in the population (Fig. 3). Size selectivity to the mixed gear fishery $\mathrm{SL}_{50}$ was calculated as $25 \mathrm{~cm} \mathrm{SL}$ and SL $9530 \mathrm{~cm}$ SL (Fig. 4).

The model was particularly sensitive to values of $L_{\text {infi }}$ increased asymptotic length to the maximum value (Table 1) yielded an SPR of zero (Table 2). An unrealistically small value, i.e. if the largest observed individual was of the asymptotic length, yielded a

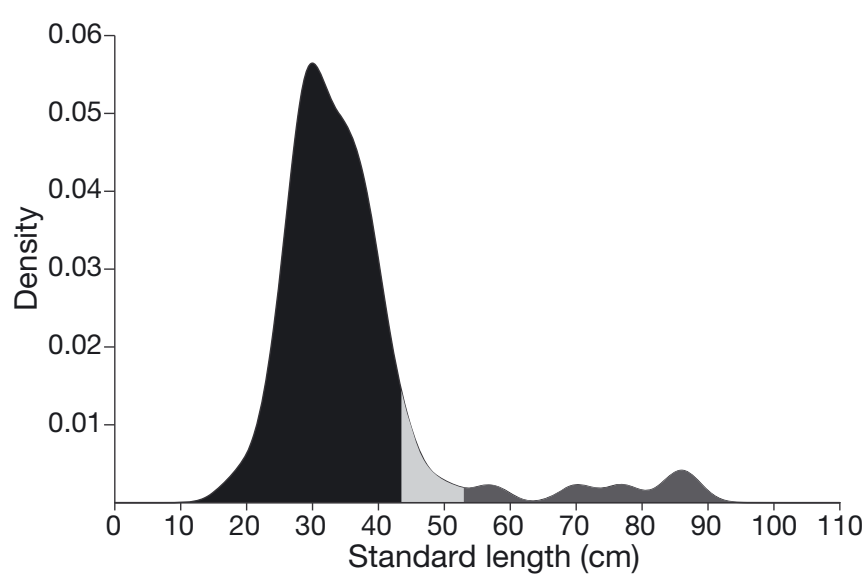

Fig. 2. Density distribution of the standard lengths of 70 Napoleon wrasse Cheilinus undulatus captured in the subsistence fishery at Anaa Atoll, French Polynesia, between 2015 and 2018. Shading corresponds to presumed stages of maturity of the protogynous hermaphrodite, which is immature (black) until $43 \mathrm{~cm} \mathrm{SL}$, beyond which it is assumed to be $50 \%$ mature (light grey) and at $53 \mathrm{~cm}$ SL it is assumed to be $50 \%$ transitioned to male sex fish (dark grey) based on values from Choat et al. (2006)

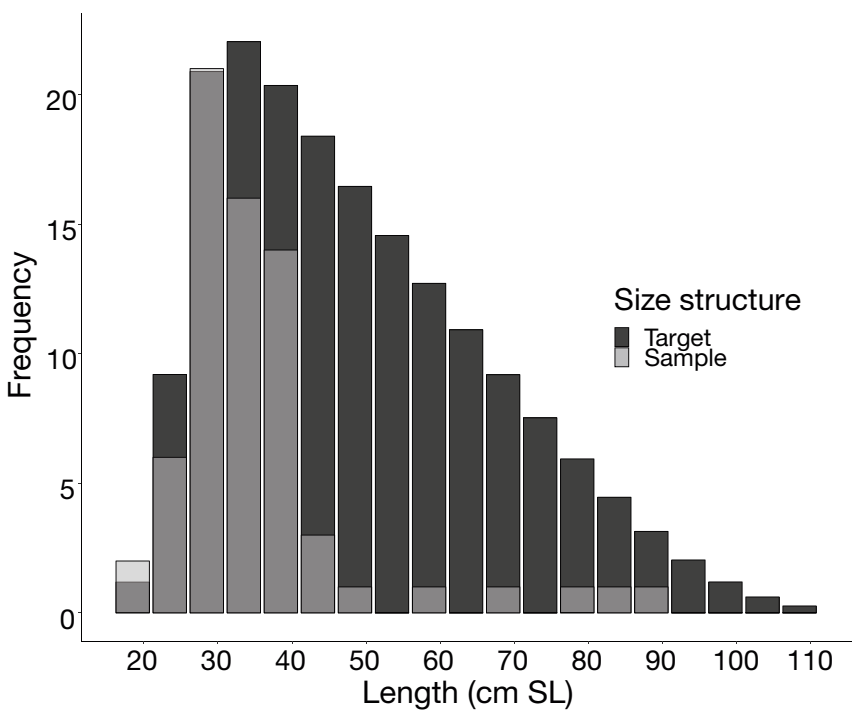

Fig. 3. Target and sampled length frequencies of the Napoleon wrasse in Anaa Atoll. Lightly shaded bars indicate the frequency of observed length groups (in $2 \mathrm{~cm}$ SL bins) with a modeled spawning potential ratio of $6 \%$. Dark shaded bars indicate the simulated target frequency distribution of length groups for a harvested population with $40 \%$ spawning potential ratio; very light grey: overlap of distributions

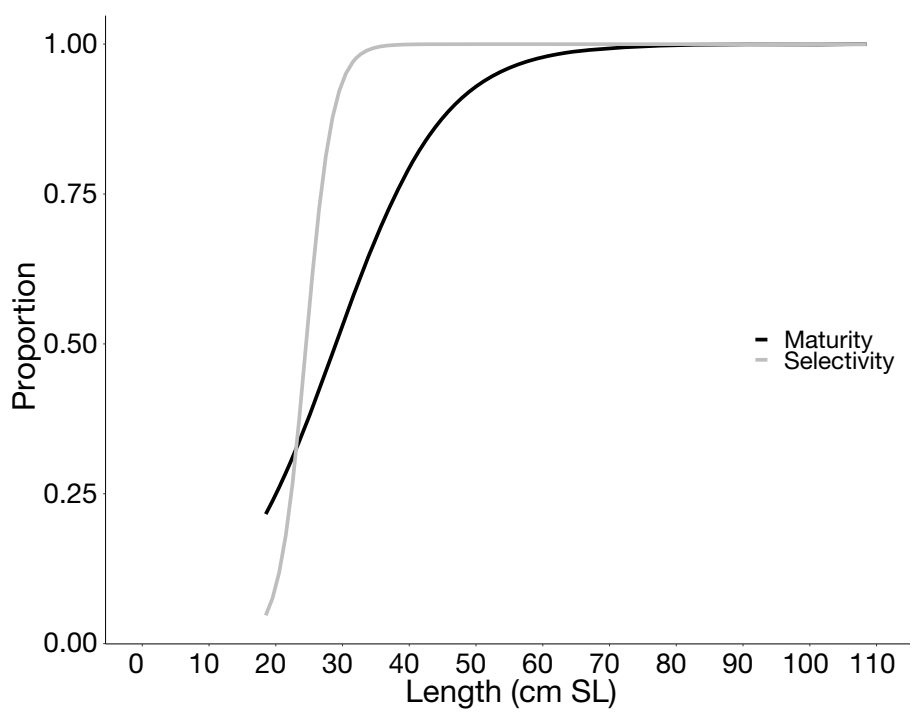

Fig. 4. Selectivity curve modeled for Napoleon wrasse in Anaa Atoll based on standard lengths measured from 70 Napoleon wrasse harvested by subsistence anglers. Selectivity (grey) is maximized at a length shorter than the length at maturity (black) in this mixed gear fishery

larger value of SPR but still one suggestive of overexploitation (Table 2). Importantly, a change in the rate of natural mortality to the value estimated by Kitalong et al. (1994, Table 1), which is very close to the rate that was calculated using the Pauly (1980) method in this study, yielded a larger SPR equal to 0.19 . 
Table 2. Results of LBSPRfit function yielding the spawning potential ratio of Napoleon wrasse Cheilinus undulatus in Anaa Atoll, French Polynesia. The row in bold font indicates the model we presented with values of asymptotic length $\left(L_{\text {inf }}\right)$ and growth rate $(K)$ from Kitalong et al. (1994), length at 50 and $95 \%$ maturity ( $L_{50}$ and $L_{95}$ ) from Choat et al. (2006) as calculated by Sadovy et al. (2007), natural mortality $(M)$ calculated from the presenst study, and the ratio of growth rate to natural mortality (MK). Note that lengths are presented as standard lengths and converted from fork length as needed (see Section 2). SPR: spawning potential ratio. Measurements of length are cm SL

\begin{tabular}{|c|c|c|c|c|c|c|c|}
\hline$L_{\mathrm{inf}}$ & $L_{50}$ & $L_{95}$ & $M$ & $K$ & MK & SPR & Comments \\
\hline 104 & 29 & 53 & 0.14 & 0.1 & 1.3 & 0.06 & Model as presented \\
\hline 87 & 29 & 53 & 0.14 & 0.1 & 1.3 & 0.20 & Model if the max length we observed was equal to $L_{\text {inf }}$ \\
\hline 292 & 29 & 53 & 0.14 & 0.1 & 1.3 & 0.00 & Model with largest $L_{\text {inf }}$ value, from Choat et al. (2006) \\
\hline 104 & 36 & 43 & 0.14 & 0.1 & 1.3 & 0.05 & $\begin{array}{l}\text { Model if } L_{50} \text { and } L_{95} \text { are presented from Choat et al. (2006) } \\
\text { without the modification suggested by Sadovy et al. (2007) }\end{array}$ \\
\hline 104 & 51 & 65 & 0.14 & 0.1 & 1.3 & 0.03 & $\begin{array}{l}\text { Model if } L_{50} \text { and } L_{95} \text { are adjusted to male and female length } \\
\text { at maturity from Sadovy et al. (2007) }\end{array}$ \\
\hline 104 & 29 & 53 & 0.26 & 0.1 & 2.6 & 0.19 & $\begin{array}{l}\text { Model with natural mortality from Kitalong et al. (1994) instead } \\
\text { of the one we calculated }\end{array}$ \\
\hline 104 & 29 & 53 & 0.26 & 0.1 & 2.6 & 0.19 & $\begin{array}{l}\text { Model with the natural mortality calculated for the population in } \\
\text { Anaa using the Pauly (1980) method rather than Hoenig (1983) }\end{array}$ \\
\hline 292 & 29 & 53 & 0.26 & 0.1 & 2.6 & 0.01 & $\begin{array}{l}\text { Model with largest } L_{\text {inf }} \text { value and with the larger value of } \\
\text { natural mortality }\end{array}$ \\
\hline 104 & 29 & 53 & 0.14 & 0.163 & 0.8 & 0.02 & Model with faster growth rate for females from Sadovy et al. (2007) \\
\hline
\end{tabular}

\section{DISCUSSION}

Napoleon wrasse Cheilinus undulatus is rare throughout its range, and population declines from human activities have yielded it the status of Endangered (Sadovy et al. 2003, Choat et al. 2006). The species is particularly threatened by overexploitation (Kindsvater et al. 2017) and appears to be overexploited in Anaa Atoll based on values of natural and fishing mortality calculated with the Hoenig (1983) and Beverton-Holt estimators at rates higher than those estimated for Palau (Kitalong et al. 1994). Importantly, Napoleon wrasse was not among the $25 \%$ most important species to subsistence fishers in Anaa, suggesting that these results were obtained in the absence of a directed fishery (A. Filous et al. unpubl. data). Our study therefore highlights how even relatively small-scale, non-selective fishing in subsistence fisheries can imperil Napoleon wrasse. Symptomatic of many overexploited populations, Napoleon wrasse appears to be completely recruited to the subsistence fishery on Anaa prior to attaining sexual maturity. This is exacerbated by their protogynous life history such that they are also completely recruited to the fishery before they have the opportunity to change sex.

Gigantic size is inherently rare even in unfished populations of Napoleon wrasse (Choat et al. 2006). A principal assumption of the SPR approach is that the length distribution of the fishery reflects the true population size distribution. Other studies have suggested cross-validation of the fishery-dependent data with fishery-independent surveys (e.g. snorkel surveys), but Choat et al. (2006) found that crypsis of small individuals under-represented them in visual surveys. Our approach also mixes gear types and capture years to ensure adequate sample size with a catch distribution that accurately represents the size structure of the population based on observations of fisher activity. The entirety of the lagoon is exploited by fishers, including the deeper reaches of the outer reef where the largest Napoleon wrasse are expected to live (although they were also encountered and captured inside the lagoon). Areas are, however, not equally accessible given that most citizens are concentrated in the village, meaning that more distant sites receive less fishing pressure. Harvested Napoleon wrasse were nonetheless measured from sites throughout the atoll. Large animals along the right tail of the distribution comprised a small proportion of the fishery catch, but their large size did not prohibit selection; fishers used mixed gears including spearguns that rendered every edible size class of fish vulnerable to harvest. Because fishers serve no market, there is no selection for any size class, such as plate-sized fish that are preferred in international markets (e.g. Kindsvater et al. 2017). Fish are rarely targeted specifically except during certain times when they are known to be vulnerable (e.g. flying fish at the full moon, bonefish during the spawning migration; A. Filous et al. unpubl. data); therefore, Napoleon wrasse are encountered opportunistically by fishers on trips to gather food. Napoleon wrasse are therefore not targeted during periods of espe- 
cially high vulnerability (e.g. Booth 2017), so there is less artificial selection that could truncate the size distribution. Indices of selectivity also suggest that the small size classes are numerically more abundant and appear to be overrepresented in the fishery catch. The mobility of fishers, diversity of gear types used to select all size classes, and desirability of Napoleon wrasse as a food fish (despite the risks of ciguatera toxicity, which we observed in one instance) render it vulnerable to exploitation by fishers throughout the atoll.

\subsection{Modelling spawning potential ratio}

Input parameters can influence the model outcome, but for data-poor fisheries it is necessary to consider the value of available information. Natural mortality is one of the most difficult metrics to define for wild species; therefore, models are relied upon for estimates (Kenchington 2014). The natural mortality we calculated by the Hoenig method was similar to that used by Kindsvater et al. (2017). The value calculated by the Pauly method is larger and similar to that calculated for Palau or Australia (Kitalong et al. 1994). Depending on whether the Hoenig or Pauly method of calculating natural mortality is relied upon, the SPR could be slightly larger, with the Pauly method suggesting an SPR of $19 \%$. A test of empirical relationships of size, growth rate, and temperature with natural mortality suggested temperature is poorly related to the rate of natural mortality, a factor that yields skepticism about the precision of the Pauly estimation (Gislason et al. 2010). However, any modeled estimate is likely to have a broad confidence interval (Gislason et al. 2010), which is why we tested several different estimators to check the sensitivity of the SPR model given uncertainties about Napoleon wrasse life history in this population. The true $L_{\text {inf }}$ of this population is unknown, a factor that can influence the outcome of SPR models (Prince et al. 2015a). We opted for the $L_{\text {inf }}$ of $138 \mathrm{~cm}$ FL (Kitalong et al. 1994), shorter than the maximum observed length of $229 \mathrm{~cm}$ SL reported by FishBase. Choat et al. (2006) reported the asymptotic length to be $397 \mathrm{~cm}$ FL for male Napoleon wrasse, albeit with an error of $2046.0 \mathrm{~cm}$, reflecting the difficulty in collecting large males and emphasizing the uncertainty surrounding the life history of this protogynous fish, particularly given that few populations are unexploited representatives of the true demographic values. The selection of $L_{\text {inf }}$ invariably affected our estimates because total mortality, and therefore fishing mortality and exploitation, as well as the length-based spawning potential ratio, depend on the assigned value of $L_{\text {inf }}$ (Hordyk et al. 2015). However, it appears that error from overestimation of $L_{\mathrm{inf}}$ is more damaging than underestimation, which is why we opted for the more conservative estimate in this study (Hordyk et al. 2015). Importantly, we selected a value of $L_{\text {inf }}$ at the smaller end of the possible values, which yielded a more conservative estimate of SPR than would larger values based on our sensitivity analyses. Notwithstanding various considerations of model sensitivity, Napoleon wrasse appears to be overexploited in Anaa. Although SPR is based on egg production, populations such as Napoleon wrasse are likely sperm-limited by the quantity and quality of males in spawning aggregations (Huntsman \& Schaaf 1994). Colin (2010) observed female-biased sex ratios (6:1 to 10:1) in Napoleon wrasse spawning aggregations of Palau, but it is unknown what ratios exist in unexploited populations.

The small value calculated for the spawning potential ratio of Napoleon wrasse in Anaa falls below the $30 \%$ SPR value posited necessary for fishery sustainability on coral reefs of Puerto Rico (Ault et al. 2008) and the $40 \%$ value that we suggested as a target value. The target SPR we selected was slightly higher, closer to Kindsvater et al. (2016) who described fish species such as Napoleon wrasse (their example was a brown-marbled grouper Epinephelus fuscoguttatus) as episodic spawners characterized by slow growth and delayed maturity before producing many small larvae, proposing a target SPR of $46 \%$ at a fishing mortality of 0.20 . At higher fishing mortality as observed in Anaa, the target SPR must be higher to maintain a sustainable Napoleon wrasse population. Low SPR is symptomatic of exploited populations, and Prince et al. (2015a) estimated small SPR of Lethrinus obsoletus (3\%), Plectropomus areolatus (5\%), Scarus rubroviolaceus $(7 \%)$, and Hipposcarus longiceps $(5 \%)$ in Palauan fisheries that target reef species. Although Prince et al. (2015a) suggest variance in SPR estimates begins to stabilize above a sample size of 350, it was logistically difficult to collect enough samples from this subsistence fishery given that (1) large predators are inherently rarer on reefs, (2) Napoleon wrasse is an Endangered species and therefore expected to be disproportionately rare where it is exploited, and (3) the species is not directly targeted by fishers but only opportunistically taken when encountered and we did not make any request for additional samples. Considering this, and given the conservative values we already apply to life history parameters for calculating SPR, we 
believe we have collected enough data to confidently conclude that Napoleon wrasse is overexploited in this fishery.

\subsection{Effects of size and sex}

Protogynous sequential hermaphrodites are a relatively common phenotype on coral reefs. However, the expression of sex-changing may drastically increase vulnerability to fishing mortality when large males are removed from the population and new males are of insufficient size to fertilize eggs of an entire harem (Sato et al. 2018). At a fishing mortality equal to $0.40,>90 \%$ of egg production was lost by simulated populations of the protogynous grouper Epinephelus cruentatus (Huntsman \& Schaaf 1994). Subtracting the natural mortality from total mortality estimated for Napoleon wrasse at Anaa Atoll, we arrived at a fishing mortality beyond this value $(0.58)$ that suggests the population must be imperilled by the drastic rate of harvest that limits the egg production and presumably also the sperm production. Huntsman \& Schaaf (1994) suggested that protogyny drastically increased vulnerability to fishing mortality of grouper and that increased minimum size at harvest attenuated the damaging effects of fishing on egg production. We did not qualify the sex ratio of the Napoleon wrasse that we measured, but only 5 were larger than the length at which $50 \%$ are expected to have changed sex (Choat et al. 2006); however, there is uncertainty about the expected length of male fish, with transitions likely appearing somewhere between 51 and $62 \mathrm{~cm}$ SL but also likely some fish born as males (Sadovy et al. 2003, Choat et al. 2006, Sadovy et al. 2010). Reducing fishing mortality of small Napoleon wrasse, which are captured by many different methods in the subsistence fishery of Anaa Atoll, may be a necessary step to rebuild the population and ensure that fish survive to the size and age at which they transition to males. Timing and rate of sex change are critical variables to consider when modeling the resiliency of protogynous species to exploitation; Sato et al. (2018) suggested that slow change and inability to change during the spawning season imperilled tuskfish Choerodon schoenleinii exposed to exploitation.

\subsection{Spatial dynamics}

Capture locations in this study reflected potential differences in habitat use of small and large wrasse on the atoll. Smaller wrasse tended to be captured in the interior lagoon, whereas large individuals were captured outside the lagoon along the back reef and within the reef. The largest catches of Napoleon wrasse in this study occurred across $2 \mathrm{~d}$ in September 2017 in a critical passage between lagoon and outer reef habitats. An aggregation of small Napoleon wrasse in the passage between the lagoon and back reef was corralled into a shallow area where they were blockaded and captured by hand, a traditional fishing method (Torrente 2015). The following day, the same or a similar school in the same location was fished by handline. Traditional knowledge suggests that this behaviour is rare but typical of Napoleon wrasse at this time of year and may represent an ontogenetic dispersal from the lagoon to the outer reef. Many of the passes between islands that compose the atoll are used by subsistence fishers for trapping fish in traditional rockpile weirs. Passage through the channels that connect the lagoon to the outer reef is therefore challenging for many species (see A. Filous et al. unpubl. data). Outside the lagoon, Napoleon wrasse seems to make use of a relatively small area; Chateau \& Wantiez (2007) suggested a home range of $0.05 \mathrm{~km}^{2}$ and daily movements up to $200 \mathrm{~m}$ based on one fish monitored by passive acoustic telemetry. Filous et al. (2017) observed long-distance movements by white-tip reef sharks and giant trevally Caranx ignobilis in Molikini, Hawaii, suggesting that other predators are more mobile along the reef than Napoleon wrasse. Filling a different niche from these more mobile predators, Napoleon wrasse has a relatively unique role as a relatively stationary reef predator in this ecosystem, including as a predator contributing to the control of the corallivorous crown of thorns starfish (Randall et al. 1978). Conserving Napoleon wrasse should be emphasized in reef conservation efforts in these remote coral atolls (D'agata et al. 2016). Recent observations of Napoleon wrasse suggest that some individuals may find refuge in deep regions of the reef beyond the reach of subsistence fishers. Moreover, spearfishing can induce timidity in fishes (Sbragaglia et al. 2018). This suggests the potential for a slight underrepresentation of the largest size class in our sample (Lindfield et al. 2016), but in general, the forereef is accessible to spearfishers, and larger fish are still frequently captured by fishers.

\subsection{On management}

Although the exportation of fisheries resources from coral reefs represents a widespread threat to 
species, including Napoleon wrasse (Warren-Rhodes et al. 2003, Kindsvater et al. 2017), small-scale fisheries exclusively for subsistence can also impart substantial negative impacts upon this Endangered species. Regulating remote reef resources is arduous and requires grassroots local action to engage in community-based conservation (Cinner \& McClanahan 2006). Minimum harvestable size in Papua New Guinea is $65 \mathrm{~cm}$ FL (51 cm SL), close to the optimum size recommended by Kitalong et al. (1994) of $69 \mathrm{~cm}$ FL. The minimum size recommended for Papua New Guinea would exclude $93 \%$ of the fish in our sample from harvest. Such top-down regulations from governments have replaced traditional management practices worldwide in areas without the capacity to monitor and enforce. These regulations lack nuance to understand local traditions and cultures and must consider the likelihood of compliance. Protection of Napoleon wrasse and other reef fishes in remote communities of the Pacific is unlikely to succeed if national or international rules are implemented to restrict fisher behaviour. More research is needed on attitudes of subsistence fishers to regulations, but our observations of the fishery suggest that although fishers do not directly target the species, they seem unlikely to avoid or release one that is encountered opportunistically while fishing.

\section{CONCLUSIONS}

Napoleon wrasse is a charismatic reef predator with an important ecological role (D'agata et al. 2016). The conservation status assigned to Napoleon wrasse, 'Endangered', reflects the myriad threats that it faces as a large, slow-growing species living in one of the world's most threatened habitats (Pandolfi et al. 2003, 2011, Sadovy et al. 2003). Although many species are at risk of extinction due to overharvest in commercial fisheries, our data suggest that exclusively subsistence fishing in a relatively isolated and small community can result in critically high exploitation and small spawning potential ratio. Despite using a very conservative value of $L_{\text {Inf }}$ that certainly underestimates the maximum possible size of this gigantic fish, we estimated a seemingly catastrophically poor spawning potential ratio of $6 \%$ for this population. Data-poor fisheries methods are imperfect, and our results are inexact but are nonetheless reflective of a worrying trend for this species that is sensitive to overexploitation even where directed commercial efforts are absent. This modelling exercise demonstrates the utility of borrowing life history coefficients from data published elsewhere and applying standard length-based assessments to evaluate stock status in data-poor fisheries (see also Prince et al. 2015a). The results of our study suggest that although subsistence fisheries may appear small in scale and non-directed with respect to species, they can nonetheless imperil this large predator. Research is urgently needed in South Pacific fisheries to understand how governments can foster communityled initiatives to develop fishing conventions and practices that will rebuild and conserve these resources as populations in these regions continue to expand fishing efforts. Co-management arrangements that incorporate fishers and other local resource users in decision-making processes represent a promising path forward to benefit the Endangered Napoleon wrasse, other fish species, and resource users (Kuperan \& Abdullah 1994).

Acknowledgements. R.J.L. was supported by a Michael Smith Foreign Study Supplement and a Canada Graduate Scholarship from the Natural Sciences and Engineering Research Council of Canada. We are grateful to the fishers and people of Anaa Atoll for working together to collect data for this study.

\section{LITERATURE CITED}

Ault JS, Smith SG, Luo J, Monaco ME, Appeldoorn RS (2008) Length-based assessment of sustainability benchmarks for coral reef fishes in Puerto Rico. Environ Conserv 35:221-231

Booth L (2017) Identifying conservation strategies for groupspawning coral reef fish in the Indo-Pacific, using a case study of a protogynous giant wrasse. Consilience: J Sustain Dev 17:33-45

Chateau O, Wantiez L (2007) Site fidelity and activity patterns of a humphead wrasse, Cheilinus undulatus (Labridae), as determined by acoustic telemetry. Environ Biol Fishes 80:503-508

Choat JH, Bellwood DR (1994) Wrasses and parrotfishes. In: Paxton JR, Eschmeyer WN (eds) Encyclopedia of fishes. University of New South Wales Press, Sydney, p 211-215

Choat JH, Davies CR, Ackerman JL, Mapstone BD (2006) Age structure and growth in a large teleost, Cheilinus undulatus, with a review of size distribution in labrid fishes. Mar Ecol Prog Ser 318:237-246

Cinner J, McClanahan TR (2006) Socioeconomic factors that lead to overfishing in small-scale coral reef fisheries of Papua New Guinea. Environ Conserv 33:73-80

Colin PL (2010) Aggregation and spawning of the humphead wrasse Cheilinus undulatus (Pisces: Labridae): general aspects of spawning behaviour. J Fish Biol 76: 987-1007

* D'agata S, Vigliola L, Graham NA, Wantiez L and others (2016) Unexpected high vulnerability of functions in wilderness areas: evidence from coral reef fishes. Proc Biol Sci 283:20160128

Wulvy NK, Freckleton RP, Polunin NV (2004) Coral reef cascades and the indirect effects of predator removal by 
exploitation. Ecol Lett 7:410-416

Ehrhardt NM, Ault JS (1992) Analysis of two length-based mortality models applied to bounded catch length frequencies. Trans Am Fish Soc 121:115-122

FAO (2003) Strategy for information on the status and trends of capture fisheries. FAO, Rome

Filous A, Friedlander A, Wolfe B, Stamoulis K and others (2017) Movement patterns of reef predators in a small isolated marine protected area with implications for resource management. Mar Biol 164:2

Froese F, Pauly D (2018) FishBase. www.fishbase.org (accessed October 2018)

Gillett R, Lightfoot C (2001) The contribution of fisheries to the economics of the Pacific Island countries. Asian Development Bank, Manila

Gislason H, Daan N, Rice JC, Pope JG (2010) Size, growth, temperature and the natural mortality of marine fish. Fish Fish 11:149-158

Goodyear CP (1977) Assessing the impact of power plant mortality on the compensatory reserve of fish population. In: Van Winkle W (ed) Proceedings of the conference on assessing the effects of power plant induced mortality on fish populations. Pergamon Press, New York, NY, p 186-195

Goodyear CP (1993) Spawning stock biomass per recruit in fisheries management: foundation and current use. In Smith SJ, Hunt JJ, Rivard D (eds) Risk evaluation and biological reference points for fisheries management. Can Spec Publ Fish Aquatc Sci 120:67-81

Hoenig JM (1983) Empirical use of longevity data to estimate mortality rates. Fish Bull 82:898-903

Hordyk A (2017) LBSPR: length-based spawning potential ratio. $\mathrm{R}$ package version 0.1 .2 . https://CRAN.R-project. org/package=LBSPR

Hordyk A, Ono K, Valencia S, Loneragan N, Prince J (2015) A novel length-based empirical estimation method of spawning potential ratio (SPR), and tests of its performance, for small-scale, data-poor fisheries. ICES J Mar Sci 72:217-231

*Huntsman GR, Schaaf WE (1994) Simulation of the impact of fishing on reproduction of a protogynous grouper, the graysby. N Am J Fish Manage 14:41-52

Kayal M, Vercelloni J, De Loma TL, Bosserelle P and others (2012) Predator crown-of-thorns starfish (Acanthaster planci) outbreak, mass mortality of corals, and cascading effects on reef fish and benthic communities. PLOS ONE $7: \mathrm{e} 47363$

Kenchington TJ (2014) Natural mortality estimators for information limited fisheries. Fish Fish 15:533-562

Kindsvater HK, Reynolds JD, Sadovy de Mitcheson Y, Mangel M (2017) Selectivity matters: rules of thumb for management of plate-sized, sex-changing fish in the live reef food fish trade. Fish Fish 18:821-836

Kitalong A, Dalzell P and the South Pacific Commission (1994) A preliminary assessment of the status of inshore coral reef fish stocks in Palau. Inshore Fisheries Research Project Technical Document No. 6. South Pacific Commission, Noumea

Kuperan K, Abdullah NMR (1994) Small-scale coastal fisheries and co-management. Mar Policy 18:306-313

Lindfield SJ, Harvey ES, Halford AR, McIlwain JL (2016) Mesophotic depths as refuge areas for fishery-targeted species on coral reefs. Coral Reefs 35:125-137

Marshall TC (1964) Fishes of the Great Barrier Reef. Angus and Robertson, Sydney
Myers RA, Worm B (2003) Rapid worldwide depletion of predatory fish communities. Nature 423:280-283

Nelson GA (2017) fishmethods: fishery science methods and models in R. R package version 1.10-4. https://CRAN.Rproject.org/package=fishmethods

Olden JD, Hogan ZS, Zanden MJV (2007) Small fish, big fish, red fish, blue fish: size biased extinction risk of the world's freshwater and marine fishes. Glob Ecol Biogeogr 16:694-701

*Pandolfi JM, Bradbury RH, Sala E, Hughes TP and others (2003) Global trajectories of the long-term decline of coral reef ecosystems. Science 301:955-958

*Pandolfi JM, Connolly SR, Marhsall DJ, Cohen AL (2011) Projecting coral reef futures under global warming and ocean acidification. Science 333:418-422

*Pauly D (1980) On the interrelationships between natural mortality, growth parameters, and mean environmental temperature in 175 fish stocks. ICES J Mar Sci 39:175-192

Poh TM, Fanning LM (2012) Tackling illegal, unregulated, and unreported trade towards humphead wrasse (Cheilinus undulatus) recovery in Sabah, Malaysia. Mar Policy 36:696-702

* Prince J, Hordyk A, Valencia SR, Loneragan N, Sainsbury K (2015a) Revisiting the concept of Beverton-Holt lifehistory invariants with the aim of informing data-poor fisheries assessment. ICES J Mar Sci 72:194-203

* Prince J, Victor S, Kloulchad V, Hordyk A (2015b) Length based SPR assessment of eleven Indo-Pacific coral reef fish populations in Palau. Fish Res 171:42-58

* Purvis A, Gittleman JL, Cowlishaw G, Mace GM (2000) Predicting extinction risk in declining species. Proc Biol Sci 267:1947-1952

Randall JE, Head SM, Sanders AP (1978) Food habits of the giant humphead wrasse, Cheilinus undulatus (Labridae). Environ Biol Fishes 3:235-238

Roff G, Doropoulos C, Rogers A, Bozec YM and others (2016) The ecological role of sharks on coral reefs. Trends Ecol Evol 31:395-407

Romero FG, Injaki AS (2015) Assessment of humphead wrasse (Cheilinus undulatus), spawning aggregations and declaration of marine protected area as strategy for enhancement of wild stocks. In: Romana-Eguia MRR, Parado-Estepa FD, Salayo ND, Lebata-Ramos MJH (eds) Resource enhancement and sustainable aquaculture practices in southeast Asia: challenges in responsible production of aquatic species. RESA, Aquaculture Department, Southeast Asian Fisheries Development Center, Tigbauan

Russell B (Grouper \& Wrasse Specialist Group) (2004) Cheilinus undulatus. The IUCN Red List of Threatened Species 2004: e.T4592A11023949. http://dx.doi.org/10.2305/ IUCN.UK.2004.RLTS.T4592A11023949.en

* Sadovy Y, Kulbicki M, Labrosse P, Letourneur Y, Lokani P, Donaldson TJ (2003) The humphead wrasse, Cheilinus undulatus: synopsis of a threatened and poorly known giant coral reef fish. Rev Fish Biol Fish 13:327-364

Sadovy YJ, Punt AE, Cheung W, Vasconcellos M, Suharti S, Mapstone BD (2007) Stock assessment approach for the Napoleon fish, Cheilinus undulatus, in Indonesia: a tool for quota-setting for data-poor fisheries under CITES Appendix II Non-Detriment Finding requirements. FAO, Rome

Sadovy Y, Liu M, Suharti S (2010) Gonadal development in a giant threatened reef fish, the humphead wrasse Cheilinus undulatus, and its relationship to international trade. J Fish Biol 77:706-718 
Sato T, Kobayashi M, Kurihara T, Takebe T and others (2018) Impact of fishing losses of males on the reproductive output of the large protogynous fish, Choerodon schoenleinii. Mar Ecol Prog Ser 602:225-235

Sbragaglia V, Morroni L, Bramanti L, Weitzmann B, Arlinghas R, Azzuro E (2018) Spearfishing modulates flight initiation distance of fishes: the effects of protection, individual size, and bearing a speargun. ICES J Mar Sci 75:1779-1789

Stallings CD (2008) Indirect effects of an exploited preda-

Editorial responsibility: Uwe Krumme,

Rostock, Germany tor on recruitment of coral reef fishes. Ecology 89: 2090-2095

Torrente F (2015) Ancestral fishing techniques and rites on Anaa Atoll, Tuamotu Islands, French Polynesia. SPC Tradit Mar Resour Manag Knowl Inf Bull 35:18-25

Walters C, Martell SJD (2004) Fisheries ecology and management. Princeton University Press, Princeton, NJ

*Warren-Rhodes K, Sadovy Y, Cesar H (2003) Marine ecosystem appropriation in the Indo-Pacific: a case study of the live reef fish food trade. Ambio 32:481-488

Submitted: July 30, 2018 ; Accepted: January 15, 2019

Proofs received from author(s): February 28, 2019 